\title{
Seasonal variation in larval growth of Eri silkworm (Samia ricini Boisduval) reared on two Ailanthus species
}

\author{
Borah, R.R. ${ }^{1}$, Saikia, M. ${ }^{1}{ }^{1}$, Saikia, H. ${ }^{2}$, Borgohain, A. ${ }^{2}$, Borah, Dutta, R. ${ }^{2}$
}

\begin{abstract}
Present study was undertaken to evaluate the impact of different seasons in larval growth of eri silkworm (Samia ricini Boisduval) reared on Ailanthus species viz., borpat (Ailanthus grandis) and borkesseru (Ailanthus excelsa). The study revealed that the larval growth parameters of eri silkworm was found better in terms of larval duration, full grown larval weight and matured larval weight on the borpat leaves as compared to the borkesseru leaves. Considering the seasons, the full grown larval weight and matured larval weight were observed significantly higher during the autumn season but the shortest larval duration was observed during the late summer season.
\end{abstract}

Key words: Ailanthus, Autumn, Early summer, Eri silkworm, Late summer, Spring

\section{Introduction}

Eri culture is the cultivation of eri silkworm food plants, production of eggs, rearing of eri silkworm, spinning of cocoon for production of yarn and weaving of eri silk fabrics. Eri silkworm under family saturniidae is completely domesticated, polyphagous, multivoltine silkworm and around 5-6 crops can be raised per year depending on the availability of the host plants. Eri culture is widely practiced in Assam, Meghalaya, Arunachal Pradesh, Nagaland and Manipur of North East India. The biggest portion of eri silk production of India is contributed from Assam. In eri sector of Assam about, 2,40,939 numbers of families are engaged and the total area under eri food plants is 42,471.01 hectare (Anon., 2019a) with a production of 4764 MT eri silk during 2018-19 (Anonymous 2019b).

Study of the effects of host plants on the biology of insects is important in understanding the host suitability under different environmental conditions (Xue et al., 2010). Various workers in their earlier works on eri silkworm observed that there was a marked difference in the larval growth and development when they feed on different plants (Ahmed et al., 2015; Devi Borah et al., 2020).

\section{Author's Address}

${ }^{1}$ Department of Sericulture, Faculty of Agriculture, Assam Agricultural University, Jorhat, Assam

${ }^{2}$ College of Sericulture, Titabar, Assam Agricultural University, Assam

E-mail.: dr.moni1980@gmail.com
Nutrient content of host plant either alone or in combination plays an important role in the larval growth, development and silk productivity of eri silkworm, Samia ricini (Das and Das, 2003; Kumar and Elangovan, 2010). Apart from this, temperature and RH exert synergistic impact regarding the silkworm larval period (Morohoshi, 1969). Low temperature is always better than higher temperature concerning the productivity of silkworm and larval duration for different instars (Datta et al., 2001; Pandey and Tripathi, 2008).

Castor (Ricinus communis Linn.) and kesseru (Heteropanax fragrans Seeman) are the major host plants of eri silkworm. Other than these two host plants, eri silkworm benefits from several alternative food plants like borpat (Ailanthus grandis Prain), borkesseru (Ailanthus excelsa Roxb.), tapioca (Manihot utilissima Pohl.), payam (Evodia flaxinifolia Hook.) etc. (Chutia et al., 2014). Castor is an annual plant and the leaves become scanty during the winter season. It has to be grown fresh for every six months due to annual nature. Utilization of alternate or secondary host plants at the hour of shortage of leaves is required to meet the requirement. Ailanthus species viz., borpat and borkesseru are perennial and leaves are accessible consistently throughout the year. As being the secondary host plants, it is essential to generate data on larval characters in various seasons as healthy and vigorous larva decides the 
cocoon and yarn quantity and quality. Marked difference in the larval growth and development of eri silkworm were observed when they feed on different host plants (Devi Borah et al., 2020). Naik et al. (2010) also reported that host plants had a significant effect on life cycle, adult longevity, matured larval weight, cocoon weight, pupal weight, shell ratio percentage of eri silkworm. Therefore, the present investigation has been undertaken to know the impact of Ailanthus species leaves on larval characters of eri silkworm in various rearing seasons.

\section{Materials and Methods}

The eri silkworms were reared during the year 2018-19 following the technique suggested by Chowdhury (1982). The rearing room and the rearing appliances were disinfected with 2 per cent formalin solution three days prior to rearing. Borpat and borkesseru, two secondary host plants were used for rearing eri silkworms under the laboratory condition from $1^{\text {st }}$ instar to $5^{\text {th }}$ instar. The rearing of eri silkworms was conducted during four different seasons viz., spring (March-April), early summer (May-June), late summer (August-September), autumn (October-November). Each treatment was replicated three times consisting of 150 larvae for each host plant. The newly hatched worms were separated with feather from their egg shell and were transferred to the rearing tray $(90 \mathrm{~cm} \times 70 \mathrm{~cm} \times 7.5$ $\mathrm{cm})$. The newly hatched larvae were provided with small tender succulent leaves from both the host plants. The medium to matured leaves of both the host plants were fed subsequently with the advancement of the larval growth of the silkworms. The larvae were fed four times per day (6 am, 10 am, $2 \mathrm{pm}$, and $8 \mathrm{pm}$ ). At the time of moulting, the leaves were not provided. The spacing and cleaning of the rearing bed were practiced appropriately Spacing was maintained along with the bed cleaning for good aeration and controlling the overcrowding of worms. The full grown and matured larvae were taken for recording the weight treatment wise.

\section{Results and Discussion}

The findings regarding the larval duration of eri silkworm reared on two different Ailanthus species are presented in Table- 1 . The effect of different seasons on the larval duration of eri silkworm was found to be significantly different. The shortest larval duration was found in the late summer (19.22 days) whereas the longest larval duration was recorded in the spring season (37.78 days). Regardless of season, the eri silkworm reared on borpat leaves recorded a significantly shorter larval duration (25.11 days) compared to borkesseru leaves (26.41 days). The interaction effect due to season and host plant was found to be nonsignificant. Irrespective of host plant and season, the shorter larval duration was registered on borpat leaves in the late summer (18.50 days) whereas the longest larval duration was recorded on borkesseru leaves during the spring season (38.43 days).

Castor was reported as the most preferred host plant of eri silkworm and better performance was observed in terms of larval characters (Dutta, 2000; Deka et al., 2011). Borpat and borkesseru as an alternative host plant can be utilized for eri silkworm rearing during scarcity of castor leaves as it shows larval parameters at par with castor. Reddy et al. (1989) recorded the larval duration on castor fed eri silkworm as 22.63 days and on barkesseru fed eri silkworm to be 37.33 days. Shaw (1998) reported significantly the shortest larval duration in castor (17 days) compared to borpat (20 days), barkesseru (21.88 days) and Ailanthus altissima (26 days). However, Deori (2006) reported significantly longer larval duration in borpat (29 days) compared to borkesseru (28.50 days) and castor (22.83 days). Ahmed et al. (2015) recorded the shortest larval period $(18.33 \pm 0.58$ days $)$ while feeding with castor $\left(1^{\text {st }}\right.$ to $2^{\text {nd }}$ instar $)$ and subsequent feeding with borpat ( $3^{\text {rd }}$ to $5^{\text {th }}$ instar) during JulyAugust whereas borpat $(19.33 \pm 0.58$ days $)$ and barkesseru (22.67 \pm 0.58 days) fed worms took slightly longer period. Larval duration is an important parameter for rearing eri silkworm due to its commercial nature. Shorter larval duration is considered better for commercial exploitation because it minimizes the cost of labour, time and supply of leaves.

The results on seasonal variation of full grown larval weight (Table 2) of eri silkworm reared on two Ailanthus species were found to be significantly different. Among the different seasons, significantly the highest full grown larval weight was found during autumn $(10.08 \mathrm{~g})$ and the lowest was recorded in the early summer season (7.38g). Irrespective of the seasons, the eri silkworm reared on borpat leaves showed a significantly higher 
Seasonal variation in larval growth of Eri silkworm

Table 1: Effect of season and Ailanthus species on larval duration (days) of eri silkworm

\begin{tabular}{|l|l|l|l|}
\hline \multirow{2}{*}{ Seasons } & \multicolumn{2}{|l|}{ Host plants } & \multirow{2}{*}{ Mean } \\
\cline { 2 - 3 } & Borpat & Borkesseru & 37.78 \\
\hline Spring (Mar-April) & 37.13 & 38.43 & 24.00 \\
\hline Early summer (May-June) & 23.66 & 24.33 & 19.22 \\
\hline Late summer (Aug-Sept) & 18.50 & 19.93 & 22.03 \\
\hline Autumn (Oct-Nov) & 21.13 & 22.93 & \\
\hline Mean & 25.11 & 26.41 & \\
\hline & S.Ed ( \pm & $\mathrm{CD}(5 \%)$ & \\
\hline Seasons & 0.35 & 0.74 & \\
\hline Host plants & 0.25 & 0.53 & \\
\hline Seasons $\times$ Host plants & 0.50 & $\mathrm{NS}$ & \\
\hline
\end{tabular}

Data are mean of 3 replications, NS $=$ Non significant

Table 2: Effect of season and Ailanthus species on full grown larval weight (g) of eri silkworm

\begin{tabular}{|l|l|l|l|}
\hline \multirow{2}{*}{ Seasons } & \multicolumn{2}{|l|}{ Most plants } & \multirow{2}{*}{ Mean } \\
\cline { 2 - 4 } & Borpat & Borkesseru & 8.77 \\
\hline Spring (Mar-April) & 9.06 & 8.47 & 7.38 \\
\hline Early summer (May-June) & 7.71 & 7.05 & 8.38 \\
\hline Late summer (Aug-Sept) & 8.65 & 8.10 & 10.08 \\
\hline Autumn (Oct-Nov) & 10.24 & 9.92 & \\
\hline Mean & 8.91 & 8.39 & \\
\hline & S.Ed ( \pm ) & CD (5\%) & \\
\hline Seasons & 0.16 & 0.35 & \\
\hline Host plants & 0.12 & 0.25 & \\
\hline Seasons $\times$ Host plants & 0.23 & NS & \\
\hline
\end{tabular}

Data are mean of 3 replications, NS $=$ Non significant

Table 3: Effect of season and Ailanthus species on matured larval weight (g) of eri silkworm

\begin{tabular}{|l|l|l|l|}
\hline \multirow{2}{*}{ Seasons } & Host plants & Mean \\
\cline { 2 - 3 } & Borpat & Borkesseru & 7.05 \\
\hline Spring (Mar-April) & 7.42 & 6.68 & 5.99 \\
\hline Early summer (May-June) & 6.31 & 5.66 & 6.84 \\
\hline Late summer (Aug-Sept) & 7.11 & 6.58 & 8.14 \\
\hline Autumn (Oct-Nov) & 8.34 & 7.93 & \\
\hline Mean & 7.29 & 6.71 & \\
\hline & S.Ed (土) & CD (5\%) & \\
\hline Seasons & 0.11 & 0.24 & \\
\hline Host plants & 0.08 & 0.17 & \\
\hline Seasons $\times$ Host plants & 0.16 & NS & \\
\hline
\end{tabular}

Data are mean of 3 replications, NS $=$ Non significant

larval weight $(8.91 \mathrm{~g})$ compared to the borkesseru were found to be significant. The highest matured leaves $(8.39 \mathrm{~g})$. The interaction effect of the seasons larval weight was found in the autumn season and the host plants were found to be non- $(8.14 \mathrm{~g})$ whereas the lowest matured larval weight significant. However, the highest full grown larval was recorded in the early summer $(5.99 \mathrm{~g})$. weight was recorded in borpat leaves during the However, matured larval weight of spring $(7.05 \mathrm{~g})$ autumn season $(10.24 \mathrm{~g})$ and the lowest $(7.05 \mathrm{~g})$ was was found to be at par with the weight in the late observed in borkesseru leaves during early summer. summer season $(6.84 \mathrm{~g})$. Setting aside the seasons, The results of the effect of various seasons on the significantly the higher matured larval weight was matured larval weight (Table 3 ) of eri silkworm recorded on the borpat leaves $(7.29 \mathrm{~g})$ compared to 


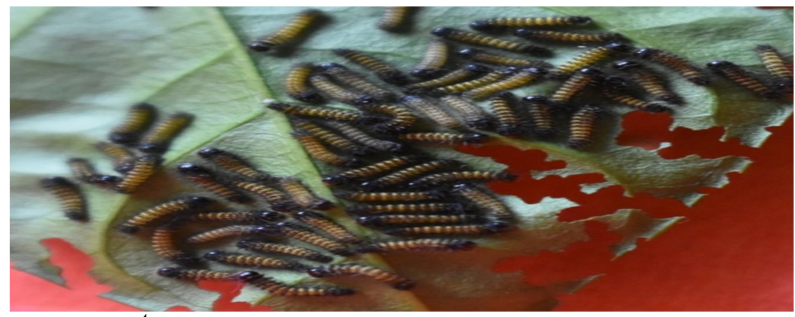

\section{$1^{\text {st }}$ instar larva}

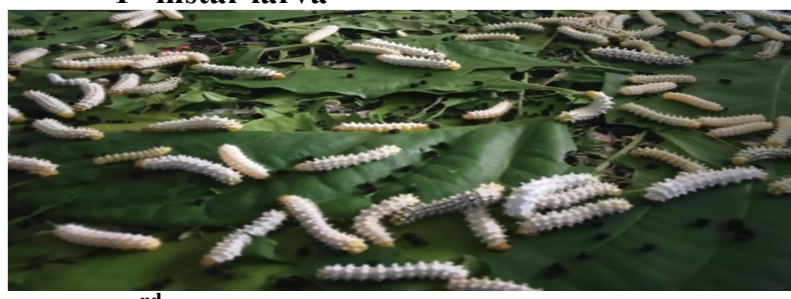

$3^{\text {rd }}$ instar larva

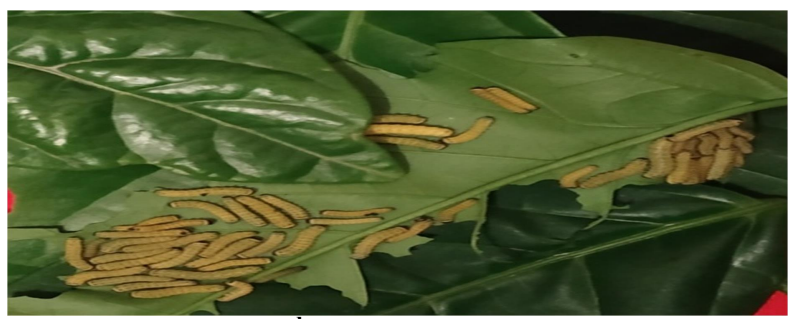

$2^{\text {nd }}$ instar larva

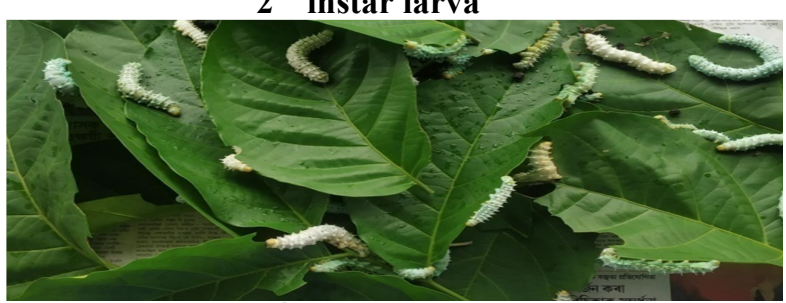

$4^{\text {th }}$ instar larva

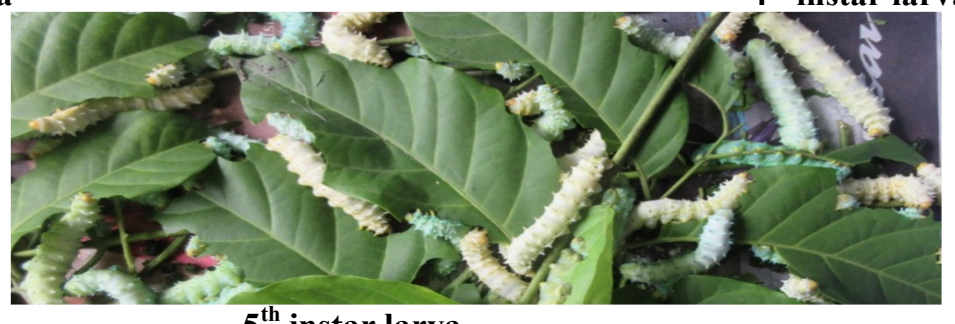

$5^{\text {th }}$ instar larva

Figure 1 : Different instars of eri silkworm larvae reared on borpat leaves.

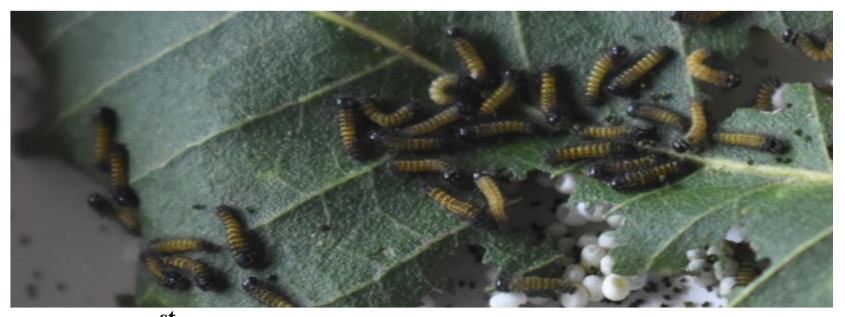

$1^{\text {st }}$ instar larva

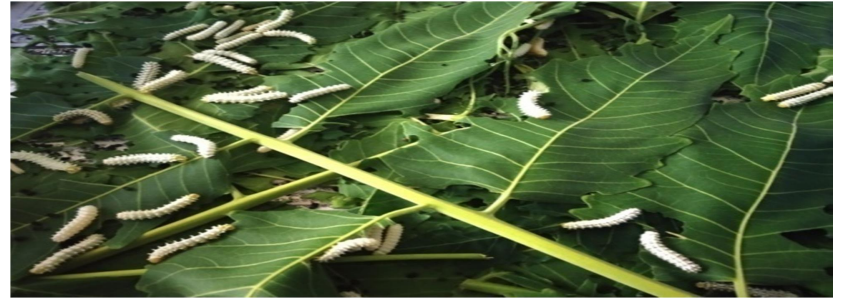

$3^{\text {rd }}$ instar larva

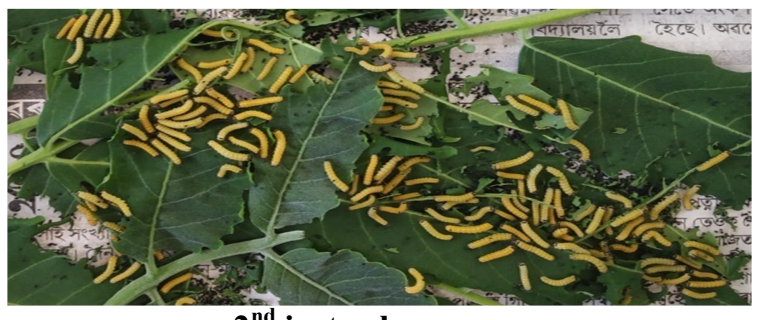

$2^{\text {nd }}$ instar larva

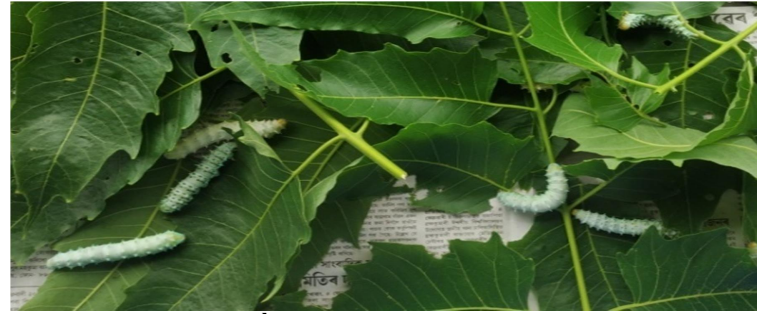

$4^{\text {th }}$ instar larva

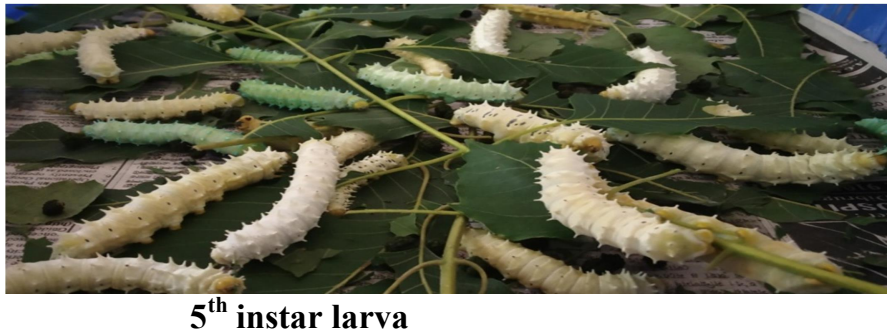

Fig. 2. Different instars of eri silkworm larvae reared on borkesseru leaves 
borkesseru leaves $(6.71 \mathrm{~g})$. The interaction effect due to seasons and host plants was found to be nonsignificant. It was observed that the highest matured larval weight was registered for the borpat leaves in the autumn season $(8.34 \mathrm{~g})$ and the lowest matured larval weight was registered for the borkesseru leaves in the early summer $(5.66 \mathrm{~g})$.

Shaw (1998) reported significantly higher larval weight in castor $(7.440 \mathrm{~g})$ compared to borpat (6.473g), barkesseru (5.652g) and Ailanthus altissima (5.120g). Dutta (2000) found that larval weight of eri silkworm was better on castor $\left(1^{\text {st }}\right.$ to $2^{\text {nd }}$ instar) interchanged with borkesseru $\left(3^{\text {rd }}\right.$ to $5^{\text {th }}$ instar). Sarmah et al. (2012) observed that castor fed eri silkworms showed the highest larval weight (7.32g) during October-November followed by May- June (7.02g) and August-September (6.66g). Ahmed et al. (2015) recorded significantly higher matured larval weight in castor + borpat $(7.61 \pm$ $0.09 \mathrm{~g}$ ) reared eri silkworm compared to borpat $(7.48 \pm 0.07 \mathrm{~g})$ and barkesseru $(7.08 \pm 0.15 \mathrm{~g})$ during September-October. Birari (2019) recorded significantly higher mature larval weight on castor followed by tapioca, barkesseru, Indian almond and on banyan tree. The life cycle routine of the silkworm from identical genetic stock varies significantly based on the nutritional quality of

\section{References}

Ahmed, S. A., Sarkar, C. R., Sarmah, M. C., Ahmed, M. and Singh, N. I. 2015. Rearing performance and reproductive biology of eri silkworm, Samia ricini (Donovan) feeding on Ailanthus species and other promising food plants. Advances in Biological Researches, 9(1): 07-14.

Anonymous. 2019a. Statistical Handbook of Assam (2018-19). Chapter-11, Sericulture, Directorate of Economics and Statistics, Govt. of Assam, pp. 133-137.

Anonymous. 2019b. Annual report (2018-19). Central Silk Board, Ministry of Textiles, Govt. of India, p. 95.

Birari, V. V., Siddhapara, M. R. and Desai A. V. 2019. Rearing performance of eri silkworm, Samia ricini (Dovovan) on different host plants. Journal of Farm Sciences,_32(4): 443-446.

Chowdhury, S. N. 1982. Eri silk industry. Directorate of Sericulture and Weaving, Govt. of Assam, Guwahati, pp. $1-177$.

Chutia, P. , Kumar, R. and Khanikar, D. P. 2014. Host Plants Relationship in terms of Cocoon Colour and Compactness leaves as reported in mulberry silkworm (Rahmathulla, 2011). The larval duration and the larval weight of the silkworm reared on different host plants show variation which might be due to the difference in energy which the larvae get from the leaves of host plants (House, 1974).

\section{Conclusion}

Present research work revealed that the late summer season and borpat leaves performed better in regards to larval duration. But full grown and matured larval weight were found better in the autumn season and borpat leaves. Thus, it can be inferred that both the plants are suitable for rearing eri silkworm in different seasons with slight variation in performance. Considering the cost of cultivation of castor and availability of borpat and borkesseru in the natural habitat of north-eastern states, the establishment of plantation in the farmer's field is an urgent requirement.

\section{Acknowledgement}

The authors are thankful to Dr. L.C. Dutta, Professor and Head of the Sericulture Department, Faculty of Agriculture, Assam Agricultural University, Jorhat -785013, Assam for his moral support and continuous encouragement.

of Eri Silkworm (Samia ricini). Biological Forum - An International Journal, 6(2): 340-343.

Das, K. and Das, R. 2003. Growth and development of muga silkworm feed on different food plants. Indian Silk, 11: 1921 .

Datta, R. K., Kumar, N. S., Basavaraja, H. K., Kumar, C. M. K. and Reddy, N. M. 2001. CSR18 × CSR19 - a robust bivoltine hybrid suitable for all season rearing in the tropics. Indian Silk, 39: 5-7.

Deka, M., Dutta, S. and Devi, D. 2011. Impact of feeding of Samia cynthia ricini Boisduval (red variety) (Lepidopera: Saturnidae) in respect of larval growth and spinning. International Journal of Pure and Applied Sciences and Technology, 5(2): 131-140.

Deori, G. 2006. Biochemical analysis of Ailanthus leaves and its impact on proximate composition of eri silkworm pupae. M.Sc. (Agri.) Thesis submitted to Assam Agricultural University, Jorhat, Assam. 
Devi Borah, S., Saikia, M. and Boro, P. 2020. Rearing performance of two selected eco-races of eri silkworm (Samia ricini Donovan) fed with castor and borpat leaves during spring and autumn season in Assam. Journal of Entomology and Zoology Studies, 8(3): 2024-2028.

Dutta, P. P. 2000. Rearing performance of eri silkworm Philosamia ricini Hutt. by interchanging castor with different host plants in different seasons. M.Sc. (Agri.) Thesis submitted to Assam Agricultural University, Jorhat, Assam.

House, H. L. 1974. Nutrition. In: Rockstein, M. (Ed.), The Physiology of Insecta, $2^{\text {nd }}$ Edition, New York, Academic. 5: 1-62.

Kumar, R. and Elangovan, V. 2010. Assessment of the volumetric attributes of eri silkworm (Philosamia ricini) reared on different host plants. International Journal of Science and Nature, 1(2): 156-160.

Morohoshi, S. 1969. The control of growth and development in Bombyx mori L. Relationship between environmental moulting and voltine characters. In. Proceedings of the Japan Academy, 45: 797-802.

Naik, C. M., Patil, G. M., Murthy, C., Awaknavar, J. S., Shekharappa and Alagundagi, S. C. 2010. Development and economic cocoon parameters of eri silkworm Samia ricini Boisduval (Lepidoptera: Saturnidae) as influenced by new hosts. Karnataka Journal of Agricultural Sciences, 23(5): 716-721.

Pandey, P. and Tripathi, S. P. 2008. Effect of humidity in the survival and weight of Bombyx mori L. larvae. Malaysian Applied Biology Journal, 37: 37-39.

Rahmathulla, V. K. 2011. Management of climatic fractors for successful silkworm (Bombyxmori Bombyxmori L.) crop and higher silk production: a review. Psyche, 1-12.

Sarmah, M. C., Ahmed, S. A., Sarkar, B. N., Debraj, Y. and Singh, L. S. 2012. Seasonal variation in the commercial and economic characters of eri silkworm Samia ricini (Donovan). Munis Entomology \& Zoology Journal, 7(2): 1268-1271.

Shaw, C. 1998. Evaluation of Ailanthus species in relation to nutrition, growth and cocoon characters of eri silkworm, Philosamia ricini Hutt. M.Sc. (Agri.) Thesis submitted to Assam Agricultural University, Jorhat, Assam.

Xue, M., Pang, Y. H., Wang, H. T., Li, Q. L. and Liu, T. X. 2010. Effects of four host plants on biology and food utilization of the cutworm, Spodoptera litura. Journal of Insect Science, 10: 1-14. 